\title{
Relationship between Nonverbal Behavior of Consultants and Consultees: A Preliminary Study
}

\author{
Kouji Oishi \\ Rikkyo University, Saitama, Japan \\ Email:oishi@rikkyo.ac.jp
}

How to cite this paper: Oishi, K. (2017). Relationship between Nonverbal Behavior of Consultants and Consultees: A Preliminary Study. Psychology, 8, 828-836. https://doi.org/10.4236/psych.2017.86053

Received: March 25, 2017

Accepted: April 25, 2017

Published: April 30, 2017

Copyright $\odot 2017$ by author and Scientific Research Publishing Inc. This work is licensed under the Creative Commons Attribution International License (CC BY 4.0).

http://creativecommons.org/licenses/by/4.0/

\begin{abstract}
Little is known about the relationship between the nonverbal behavior of consultants and consultees in problem identification interviews in behavioral consultations. In particular, despite its assumed importance to consultative relationships and consultation success, the effects of nonverbal behavior on behavioral consultations remains unexplored. This short case report describes a study which sought to determine how nonverbal behavior from consultants can control the behavior of consultees. We recorded the occurrence or nonoccurrence of gestures and nodding responses and examined the association between these nonverbal behaviors in consultants and consultees by lag sequential analysis of videotaped sessions. The consultations involved two consultants and one consultee. The consultee presented the cases of two clients with distinct clinical problems and discussed solutions in two consultation sessions with each consultant, for a total of four consultation sessions. Our findings suggest that the experiential differences of consultants influenced the use and effect of nonverbal behaviors in behavioral consultations. Lag sequential analysis further showed that a consultant's nonverbal behavior, such as hand gestures, controlled that of the consultee. However, the promotional impact of nodding responses by the consultee in response to the experienced consultant was not observed in response to the less experienced consultant. Although our findings were derived from a single consultation series involving only four consultation sessions, they highlight the importance of nonverbal behavior for behavioral consultation success and suggest that consultant education and training programs for nonverbal behavior be continually updated with new knowledge to improve consultation success.
\end{abstract}

\section{Keywords}

Nonverbal Behavior, Behavioral Consultation, Problem Identification Interview, Social Power, Lag Sequential Analysis 


\section{Introduction}

In 2002, Erchul and Martens introduced social power variables to behavioral consultation techniques. They examined how the behavior of consultants controls that of consultees in behavioral consultations; they termed this control "social power", and defined it as the potential for "a change in the belief, attitude, or behavior of a target of influence, which results from the action or presence of an influencing agent" (Erchul \& Martens, 2002). Their research on the social control process of behavioral consultations showed that the spoken messages of consultants and consultees affect the outcomes of behavioral consultations (Erchul et al., 2007). In 2014, Erchul et al. discussed social power and interpersonal influence within school consultations. Here, they defined the concept of social power as "understanding and explanation that the thought, feeling, and behavior of individuals are influenced by the presence of others". Nonverbal behavior in behavioral consultations may also have such social control power (Babad \& Peer, 2010). Therefore, research regarding nonverbal behavior in behavioral consultations is important.

A typical example of social control power is the media bias effect. Research indicates that a third party's perception of an interviewee is influenced by the nonverbal behaviors of the interviewer (Babad \& Peer, 2010). Furthermore, Montague et al. (2011) examined nonverbal behavior such as eye gaze orientation between clinicians and patients in a medical setting using lag sequential analysis and proved that nonverbal behavior is important for achieving trust within multiuser health care settings. Moreover, studies into the influence of nodding found that the sequential placement of a therapist's nods and smiles were influenced by the quality of rapport with the client (Muntigl et al., 2012a; Muntigl et al., 2012b).

Nonverbal behaviors such as tone of voice and facial expressions are also important variables in the behavioral consultation process (Dinkmeyer et al., 2016). Sangganjanavanich and Lenz (2012) proposed that professional skills include the ability to conceptualize issues and to communicate these with the consultee; professionalism when interacting with the consultee; and ethical practice. Rathel and Christle (2008) showed the importance of nonverbal gestures in school settings. They showed that performance feedback to pre-service teachers from supervisors in behavioral consultations can act to improve teachers' nonverbal communication skills and classroom management and climate, which in turn enhanced the academic progress of students with emotional and behavioral disorders. However, few studies have examined the social and communication factors behind behavioral consultations. Moreover, it is unclear how a consultant's nonverbal behavior can directly affect that of a consultee.

This study sought to examine how the nonverbal behavior of consultants directly controls the behavior of consultees. Understanding the relationship between the nonverbal behavior of consultants and consultees can be useful for developing behavioral consultation education and training programs for consultants. 


\section{Method}

\section{Participants}

All participants were provided with an explanation of the research purpose and research methods of this study, and informed consent was obtained for participation and publication of the research. This study was approved by the Psychology Research Ethics Committee of Rikkyo University (approval number: 14-01).

Participants consisted of one consultee and two consultants. All participants were Japanese. The consultee was a female aged in her late 40s with more than 20 years of high school teaching experience, and was the chief educational consultant in her school. Both consultants were certified Clinical Psychologists in Japan and were child development support experts experienced in providing comments, suggestions, and advice to teachers. Consultant A was a male aged in his late 40 s with more than 20 years of experience. Consultant B was also male, aged 30 years with between 5 and 10 years of experience. Both consultants had been educated and trained in clinical psychological interventions based on applied behavioral analysis while enrolled at university and graduate school, and had experience working as counselors at public school counseling centers after completion of graduate school. Excluding experience, the behavioral consultation knowledge and skill level of the two consultants was considered to be similar.

Procedure

While most behavioral consultations generally involve direct contact between the consultant and client, here we adopted an indirect method to solve the clients' clinical problems. The consultee presented the cases of two Japanese school-aged clients with distinct clinical problems to the consultants. The first client was a girl who refused to attend school and exhibited poor social and physical activity, while the second client was a boy who had ceased attending school and required intervention by family members for intermittent truancy. The clients did not participate directly in this study. Each consultant conducted two consultation sessions with the consultee to discuss solutions to the clinical problems of the clients, with one client discussed per consultation. The consultants conducted problem identification and problem analysis interviews for the clients (Bergan \& Kratochwill, 1990).

Consultant and consultee sat by face to face. Consultants asked consultee to speak freely what is currently in trouble with a client. Also asked to express consultee's idea about the background and cause of client's problem. While listening to the explanation of consultee, consultants did necessary analized and reported it to consultee. These reports followed the idea of applied behavior analysis.

The behavioral consultations of the consultants were supported by empirical evidence based on the functional understanding of behavior (Dufrene et al., 2016). To offset any order effects, the consultation counterbalance method was used; that is, Consultant B conducted the first interview in the first session while Consultant A conducted the first interview in the second session. 
The consultation interviews reflected the problem identification interviews of behavioral consultations. The consultant conducted a consultation for $30 \mathrm{mi}-$ nutes after confirming the consultee's main complaint. The first 10 minutes of the consultation were video recorded and divided into 60 intervals for analysis. The author and a graduate student, who did not know the purpose of this study, recorded the target behaviors (see below). We recorded the occurrence or nonoccurrence of these target behaviors using the interval recording method (Barlow \& Hersen, 1984). All observations were made independently. We did not inform the consultants of the contents of the analysis in advance.

\section{Measures}

We analyzed the nonverbal behavior between the consultants and consultee to determine the influence of the nonverbal behavior of consultants on that of the consultee. Nonverbal behavior including eye gaze, nodding and smiling are important variables in behavioral consultations. Observation of eye gaze was difficult because precision instruments such as eye tracking devices were not used. Instead, we observed the consultants and consultee for target behaviors including gestures and smiling reaction responses for consultants, and gestures and nodding responses for the consultee. We hypothesized that nodding and smiling during the behavioral consultation process might affect rapport building. These nonverbal behaviors were easy to observe and allowed relatively reliable observation and recording. The behaviors of the consultants in the two consultation sessions with the consultee (one session per client) were averaged and examined for their influence on the consultee.

Ianiro et al. (2015) showed that lag sequential analysis can be used to examine interdependencies between behaviors and interactions at the micro level over time. We used lag sequential analysis to examine how the nonverbal behavior of the consultant controls that of the consultee. To use this analysis method, we first examined the occurrence pattern of nonverbal behavior for each consultant and the conditioned probability of the occurrence of nonverbal behavior by the consultee. Lag sequential analysis compares the difference between the conditional probability of a following behavior, given a preceding behavior, from the unconditional probability of the following behavior ( $\mathrm{Z}$ scores). The $\mathrm{Z}$ score was then used to determine whether or not the obtained conditional probability exceeded the expected value; that is, the influence of Consultant A and B's behaviors (gestures and smiling responses) on those of the consultee (gestures and nodding responses). $Z$ scores $\geq 1.96$ or $\leq-1.96$ were considered significant ( $p<$ 0.05) (Bakeman \& Gottman, 1997).

\section{Results}

We analyzed the nonverbal behavior between consultants and the consultee to determine the influence of the nonverbal behavior of consultants on that of the consultee. The occurrence or nonoccurrence of gestures, and smiling and nodding reactions were examined using the interval recording method. Trial reliability was determined for the results observed by the interval recording method 
for 10 seconds. Average interobserver reliability was $91.1 \%$ (range: $77.5 \%$ to $100.0 \%)$.

Gestures performed by the consultee included movement of the hand to represent the movements of the body of the client, that of objects envisioned by the consultee, and body movements of the client during interactions with teachers. The consultee also used movement of the upper body to express interactions with colleagues. In contrast, gestures performed by the consultants included squeezing and movement of hands in the direction of the consultee to represent interactions between the consultee and client as understood by the consultant. In response, the consultee showed strong consent by nodding in the consultation session with Consultant A.

We analyzed the influence of nonverbal behaviors of the consultants on the nonverbal behaviors of the consultee using lag sequential analysis. As shown in Table 1, both consultants performed gestures that significantly suppressed those of the consultee (Consultant A: $\mathrm{z}=-3.23, p<0.05$; Consultant $\mathrm{B}: \mathrm{z}=-2.60, p<$ $0.05)$.

Interestingly, Consultant A performed gestures that promoted the consultee's nodding response, an association that was not significant for the less experienced Consultant $\mathrm{B}$ (Consultant $\mathrm{A}: \mathrm{z}=3.23, p<0.05$; Consultant $\mathrm{B}: \mathrm{z}=1.84$, n.s.).

Figure 1 shows the cumulative frequency of nonverbal behaviors (gestures) performed by Consultant $\mathrm{A}$ and Consultant $\mathrm{B}$, and that of the nodding response of the consultee. Qualitatively, only the nonverbal behaviors (gestures and nodding response) of the Consultant A-consultee pair showed a strong association: Consultant A's gestures and the consultee's nodding response showed the same trend until the 26th interval. After the 27th interval, the consultee's nodding response exceeded the cumulative frequency of Consultant A's gestures, suggesting that the consultee's nonverbal behavior was strongly motivated by the behavioral consultation with Consultant A.

Therefore, gestures performed by the consultants suppressed the gestures of the consultee but prompted nodding responses in the consultee; however, the latter were not detected in sessions with the less experienced consultant. Interestingly,

Table 1. Z scores of conditional probabilities of nonverbal behavior of consultants and the responses of the consultee.

\begin{tabular}{ccc}
\hline \multirow{2}{*}{ Variable } & \multicolumn{2}{c}{ Consultee nonverbal response behavior at lag 1} \\
\cline { 2 - 3 } & Gestures & Nodding \\
\hline \multirow{2}{*}{ Gestures } & Preceding Consultant A nonverbal behavior & \\
Smiling & $-3.23^{*}$ & $3.23^{*}$ \\
& 1.5 & -0.23 \\
Gestures & Preceding Consultant B nonverbal behavior & \\
Smiling & $-2.60^{*}$ & 1.84 \\
\hline${ }^{*} p<0.05$. & 0.54 & 0.53 \\
\hline
\end{tabular}




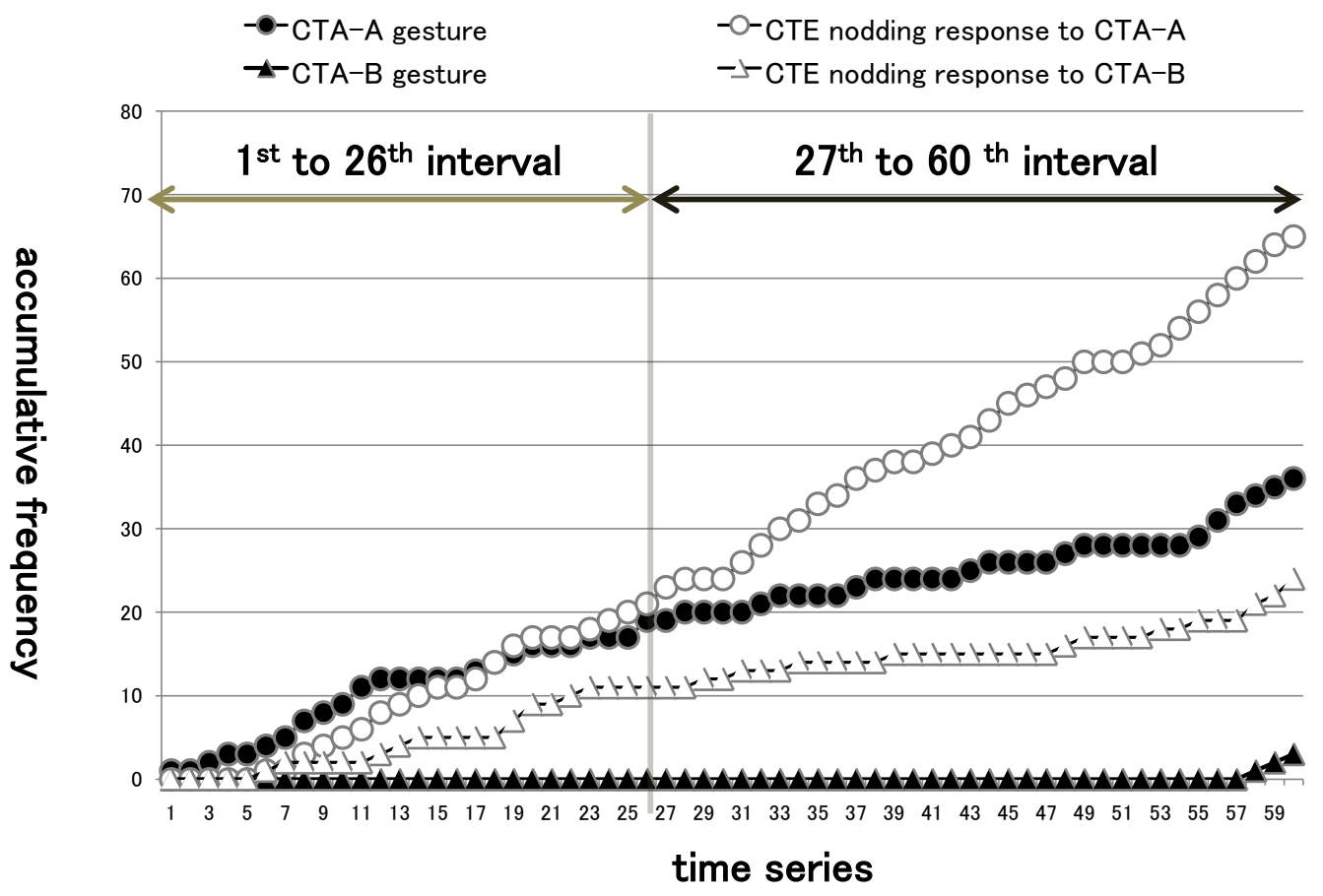

Figure 1. Cumulative frequency of the nonverbal behavior of the consultants and consultee across 60 intervals in 10 minutes, $(\mathrm{CTA}=$ consultant, $\mathrm{CTE}=$ consultee $)$.

however, no difference was found between the types of gestures performed by the consultants.

We also examined the effects of consultants' smiling responses on the gestures and nodding responses of the consultee; no significant differences were detected for either consultant.

\section{Discussion}

Nonverbal behavior including eye gaze, nodding and smiling are important variables in behavioral consultations. However, the effect of nonverbal behavior on the behavioral consultation process is unknown. This study addressed the social power that a consultant's nonverbal behavior exerts upon a consultee. We showed the nonverbal behaviors of consultants can both suppress and motivate those of a consultee in behavioral consultations.

We used lag sequential analysis to show that a consultant's gestures can control the nonverbal behavior of consultees. This association was particularly clear between the consultee and Consultant $\mathrm{A}$, who has extensive consultation experience. More experienced consultants have been shown to possess better verbal counseling performance than inexperienced consultants (Benn et al., 2008). We showed that such differences might also be present in behavioral consultations: Consultant A's gestures promoted nodding responses from the consultee, but Consultant B's did not. However, no difference was found in the types of gestures performed by the consultants, suggesting that the verbal content of the consultants may have differed. Our preliminary observations suggest that Consultant A used richer vocabulary and drew on various examples during the con- 
sultation. Therefore, the effectiveness of the more experienced consultant's gestures may have been enhanced by better verbal content. Future research should examine the effects of both verbal and nonverbal behaviors. Our results suggest that differences in experience may influence the use and/or effectiveness of nonverbal behaviors in behavioral consultations.

Our results indicate that consultants who conduct behavior consultations should be sensitive to their own nonverbal behaviors; doing so will improve the success of behavioral consultations (Fufrene et al., 2016). Although we used an indirect behavioral consultation paradigm, such consultations generally involve direct contact between the consultant and client. Therefore, given that the nonverbal behavior of a consultant affects the nonverbal behavior of the client, the consultant's nonverbal behavior will have a major impact on the successful resolution of the client's clinical problems. Rathel and Christle (2008) showed that nonverbal gestures were an important part of teacher communication with students. They showed that feedback from a supervisor enabled two female pre-service teachers to improve classroom management and climate to enhance the progress of students with emotional and behavioral disorders (Rathel \& Christle, 2008). In our study, the consultee, who was the chief educational consulting teacher in her school, presented the cases of two school-aged clients with distinct clinical problems. Such behavioral consultations are expected to help the consultee and her fellow teachers to better solve the problems of their student clients and promote concrete intervention methods at the school.

Babad and Peer (2010) has emphasized the importance of a consultee's nonverbal behavior in the behavioral consultation process. Thornberg (2014) suggests that within a school consultation environment, a conflict between external consultants and consultee school personnel can hinder the professional development of consultee teachers. Therefore, it is important to consider the length of time for which a consultee shows consent by a nodding response in behavioral consultations. Future studies are needed to examine this in consecutive consultations.

A limitation of this short case report is that it examines a single consultation series involving only four consultation sessions. Thus, we cannot assess the extent of the consultant's social power on the nonverbal behavior of consultees. Further, our consultants and consultee/clients consisted of Japanese participants; therefore, our results may not be generalizable, and additional case studies are required for verification. Also, we could not observe the eye gaze in the process of collecting nonverbal behaviors of the consultants and consultee. This point was also one of the limitations of this short case report. Additionally, we did not simultaneously examine the verbal behavior of consultants and consultees; therefore, it is possible that some of the observed associations may also be due to verbal behaviors. Future studies should determine the comparative influence of verbal and nonverbal behaviors on the nonverbal behavior of consultees.

Our results indicate that it is important to pay attention to nonverbal behaviors such as gestures in behavioral consultations to achieve effective responses 
from consultees. In a school consultation setting, changing the behavior of pre-service teachers can improve the learning environment and therefore solve the clinical problems of school-aged clients. Therefore, we propose that it is necessary to continuously update nonverbal behavior in consultant education and training programs with new knowledge and findings to improve consultation outcomes.

\section{Impact and Implications Statement}

This short case report examined nonverbal behavioral interactions between consultants and a consultee in behavioral consultations concerning the conduct of school-aged clients. Previous research indicates that nonverbal interactions influence the consultation process and outcome. Knowledge of these behavioral cues will contribute to improving consultation skills to solve problems in school environments.

\section{References}

Babad, E., \& Peer, E. (2010). Media Bias in Interviewers' Nonverbal Behavior: Potential Remedies, Attitude Similarity and Meta-Analysis. Journal of Nonverbal Behavior, 34, 57-78. https://doi.org/10.1007/s10919-009-0078-x

Bakeman, R., \& Gottman, J. M. (1997). Observing Interaction: An Introduction to Sequential Analysis (2nd ed.). New York, NY: Cambridge University Press. https://doi.org/10.1017/CBO9780511527685

Barlow, D. H., \& Hersen, M. (1984). Single Case Experimental Designs: Strategies for Studying Behavior Change (2nd ed.). New York, NY: Pergamon Books.

Benn, A. E., Jones, G. W., \& Rosenfield, S. (2008). Analysis of Instructional Consultants' Questions and Alternatives to Questions during the Problem Identification Interview. Journal of Educational and Psychological Consultation, 18, 54-80. https://doi.org/10.1080/10474410701864115

Bergan, J. R., \& Kratochiwill, T. R. (1990). Behavioral Consultation and Therapy (pp. 81-195). New York, NY: Kluwer Academic/Plenum Publishers.

Dinkmeyer, D. J., Carlson, J., \& Michel, R. E. (2016). Consultation: Creating School-Based Interventions (4th ed.). New York, NY: Routledge.

Dufrene, B. A., Zoder-Martell, K. A., Dieringer, S. T., \& Labrot, Z. (2016). Behavior Analytic Consultation for Academic Referral Concerns. Psychology in the Schools, 53, 823. https://doi.org/10.1002/pits.21885

Erchul, W. P., \& Martens, B. K. (2002). School Consultation: Conceptual and Empirical Bases of Practice (2nd ed.). New York, NY: Kluwer Academic/Plenum Publishers.

Erchul, W. P., DuPaul, G. J., Grissom, P. F., Junod, R. E. V., Jitendra, A. K., Mannella, M. C. et al. (2007). Relationships among Relational Communication Process and Consultation Outcomes for Students with Attention Deficit Hyperactivity Disorder. School Psychology Review, 36, 111-129.

Erchul, W. P., Grissom, P. C., Getty, K. C., \& Bennet, M. S. (2014). Researching Interpersonal Influence within School Consultation: Social Power and Relational Communication Perspectives. In W. P. Erchul, \& S. M. Sheridan (Eds.), Handbook of Research in School Consultation (pp. 349-385). New York, NY: Routledge.

Ianiro, P. M., Lehmann-Willenbrock, N., \& Kauffeld, S. (2015). Coaches and Clients in Action: A Sequential Analysis of Interpersonal Coach and Client Behavior. Journal of 
Business Psychology, 30, 435-456. https://doi.org/10.1007/s10869-014-9374-5

Montague, E., Xu, J., Chen, P., Asan, O., Barrett, B. P., \& Chewning, B. (2011). Modeling Eye Gaze Patterns in Clinician-Patient Interaction with Lag Sequential Analysis. Human Factors, 53, 502-516. https://doi.org/10.1177/0018720811405986

Muntigl, P., Knight, N., \& Watkins, A. (2012b). Working to Keep Aligned in Psychotherapy: Using Nods as a Dialogic Resource to Display Affiliation. Language and Dialogue, 19, 9-27.

Muntigl, P., Knight, N., Horvath, A. O., \& Watkins, A. (2012a). Client Attitudinal Stance and Therapist-Client Affiliation: A View from Grammar and Social Interaction. Research in Psychotherapy: Psychopathology, Process and Outcome, 15, 117-130.

Rathel, J. M., \& Christle, C. C. (2008). Effects of Supervisor Performance Feedback on Increasing Preservice Teachers' Positive Communication Behaviors with Students with Emotional and Behavioral Disorders. Journal of Emotional and Behavioral Disorders, 16, 67-77. https://doi.org/10.1177/1063426607312537

Sangganjanavanich, V. F., \& Lenz, A. S. (2012). The Experimental Consultation Training Model. Counselor Education and Supervision, 51, 296-307.

https://doi.org/10.1002/j.1556-6978.2012.00022.x

Thornberg, R. (2014). Consultation Barriers between Teachers and External Consultants: A Grounded Theory of Change Resistance in School Consultation. Journal of Educational and Psychological Consultation, 24, 183-210. https://doi.org/10.1080/10474412.2013.846188

Submit or recommend next manuscript to SCIRP and we will provide best service for you:

Accepting pre-submission inquiries through Email, Facebook, LinkedIn, Twitter, etc. A wide selection of journals (inclusive of 9 subjects, more than 200 journals)

Providing 24-hour high-quality service

User-friendly online submission system

Fair and swift peer-review system

Efficient typesetting and proofreading procedure

Display of the result of downloads and visits, as well as the number of cited articles

Maximum dissemination of your research work

Submit your manuscript at: http://papersubmission.scirp.org/

Or contact psych@scirp.org 